\title{
Body weight perception is associated with socio-economic status and current body weight in selected urban and rural South Indian school-going children
}

\author{
Maria Pauline ${ }^{1, *}$, Sumithra Selvam², Sumathi Swaminathan ${ }^{2}$ and Mario Vaz ${ }^{1,2}$ \\ 'Department of Physiology, St John's Medical College, Koramangala, Bangalore 560034, India: ${ }^{2}$ St. John's \\ Research Institute, Koramangala, Bangalore, India
}

Submitted 24 May 2011: Accepted 3 January 2012: First published online 10 February 2012

\begin{abstract}
Objective: To evaluate the current and ideal body weight perceptions of schoolchildren in relation to their actual body weight and socio-economic status (SES). Design: Baseline evaluation of schoolchildren from January 2008 to April 2008 as part of a 3-year longitudinal study.

Setting: City and non-city locations, Karnataka State, South India.

Subjects: Schoolchildren ( $n$ 1877) aged between 8 and 14 years.

Results: Girls, children of more educated parents and city dwellers were more likely to be overweight $(P<0 \cdot 001)$. Younger children aged $<10$ years and those of lower SES were more likely to perceive themselves as underweight (adjusted $\mathrm{OR}=1 \cdot 63,95 \% \mathrm{CI} 1 \cdot 25,2 \cdot 11$ and adjusted $\mathrm{OR}=1 \cdot 87,95 \% \mathrm{CI} 1 \cdot 32,2 \cdot 65$ ). Underweight children were ten times more likely to overestimate their current weight status, while overweight children were four times more likely to underestimate it. The odds of children of lower SES underestimating their weight, as well as desiring a higher weight, were higher than those of higher-SES children. Conclusions: SES is associated with body weight perception. Underweight children are more likely to overestimate their weight status and overweight children more likely to underestimate it.
\end{abstract}

\author{
Keywords \\ Weight perception \\ Weight status \\ School-aged population
}

Overweight and obesity are emerging problems in developing countries where undernutrition and underweight continue to be highly prevalent. Thus, overweight/ obesity in affluent school-going children in India has been reported to be as high as $30 \%{ }^{(1,2)}$, while relatively recent national-level data indicate that $48 \%$ of children under 3 years of age are stunted and $43 \%$ are underweight ${ }^{(3)}$. There is also an understanding that interventions that address overweight/obesity and its associated clinical sequelae need to be targeted at younger individuals, since health-related behaviours such as physical activity often track from childhood into adulthood ${ }^{(4)}$. While there are some data in India that have related diet ${ }^{(5)}$ and physical inactivity $^{(6)}$ to childhood overweight, there is a paucity of literature across much of the developing world regarding other associated social and behavioural factors. One of these poorly studied associations is that of perceived body weight and childhood overweight/obesity, particularly in the context of a developing country with a high prevalence of children who are underweight.

Body image, the way in which an individual perceives his/her appearance in terms of shape, size and other characteristics $^{(7)}$, could conceivably be associated with acceptability of weight gain. There are societies where obesity is seen as a measure of prosperity and social standing ${ }^{(8-10)}$; something quite acceptable, or even to be aspired to. Thus people who are poor may be more likely to accept being overweight as an indication of social mobility. This has implications in societies where there are large numbers of poor people who may, as a result of improved economic conditions, undergo a nutrition transition with reduced underweight in the short term and increased overweight in the long term. In countries such as India, the nutrition transition is underway ${ }^{(11)}$, although there are large regional differences in the extent to which this has evolved ${ }^{(3)}$.

Misperception of weight status is reported in both adults $^{(10)}$ and children ${ }^{(12-15)}$, particularly among those overweight $^{(16)}$. It has been reported that children and adolescents tend to underestimate their weight ${ }^{(16,17)}$. Children of different ethnic origins, too, have different weight perceptions $^{(14,18)}$. Native Americans perceive heavier weights as normal, compared with Caucasians, while African Americans and Asian girls are less likely to perceive lower weights as being normal. African-American girls underestimate their weight and resort to weight gain compared 
with Hispanics and Latina girls, who perceive themselves as being overweight and try to lose weight. In the current analysis we studied the extent to which school-going children, studying in low and higher socio-economic schools and residing in city and non-city environments, perceived their current body weight and whether individuals of poor socio-economic status (SES) tended to perceive themselves as being thinner than they actually were (i.e. they underestimated their actual body weight status) and were more likely to aspire to a 'fatter' body image.

\section{Methods}

\section{Participants}

Out of 2083 eligible children between the ages of 8 and 14 years, 1907 children (895 boys and 1012 girls) from seven schools in the state of Karnataka, South India, consented for the study at baseline, as part of a longitudinal study with a projected follow-up of 2 years to monitor growth indices in rural and urban children. Out of these, 1877 children ( 875 boys and 1002 girls) participated in the study. The present analyses are derived from the baseline survey conducted between January 2008 and March 2008. The sample recruited was found to have adequate power (above 80\%) to identify significant sociodemographic predictors for perception of body weight in the present study and to detect overestimation/ underestimation of at least 10\% in 1907 children at 5\% level of significance.

Convenience sampling of seven schools of city and non-city (rural and small rural towns) children provided a mix of SES (based on school fees linked to the language of instruction). Thus, two schools were located in villages, three in small towns and two in Bangalore city. All schools were co-educational, non-residential and open to all children irrespective of caste, religion and mother tongue (language spoken at home). The schools in which Kannada, the regional state language, was the language of instruction received government support and had annual tuition fees of Rs 250 to 500, whereas schools with English as language of instruction did not receive government support and had annual tuition fees above Rs 6000 . Hence the language of instruction in schools was used as an indicator of SES. Three schools (one each in a village, small town and city) had Kannada as the language of instruction, while four schools (one in a village, two in small towns and one in the city) had English as the language of instruction.

Prior to enrolment, ethical approval was obtained from the Institutional Ethics Review Board of St John's Medical College. The study protocol was explained to the principal of each school and permission obtained to conduct the study. The protocol of the study was explained to each eligible child and consent forms were sent via the child to the parents. Consent was obtained from the parents and assent from each child.

\section{Body weight perception assessment}

A simple questionnaire in both Kannada and English languages was framed for young children. There were no open-ended questions. The questionnaire captured the children's body weight perceptions with regard to their current weight and their perceived ideal body weight, i.e. the weight they wished to achieve. The questionnaire was piloted on sixty children of the same age group to check if the questions were simple and easy to answer. The questionnaire was first distributed. The investigator then read each question out aloud together with its options to a group of children, and provided explanations when asked in the local languages such that all children could comprehend the question and tick their answers. Doubts were clarified and adequate time given to all children to answer the question on their individual questionnaires before proceeding to the next question. Responses on the questionnaires were obtained prior to obtaining the anthropometric measurements.

For the present analysis, current body weight perception was obtained with the statement 'I think my body weight/appearance is...' with options 'too thin', 'a little thin', 'normal', 'a little fat' or 'too fat'. Perception of ideal body weight was obtained with the statement 'I want to be...' with options 'a lot fatter', 'slightly fatter', 'as I am at present', 'slightly thinner' or much thinner'.

For analysis of current body weight perceptions, 'too thin' and 'little thin' were combined for 'perceived thinness' and 'a little fat' and 'too fat' for 'perceived fatness'. Similarly, for ideal body weight perception, responses of 'as I am at present' were considered as 'want to be as I am', 'slightly thinner' and 'much thinner' were combined as 'want to be thinner' and 'slightly fatter' and 'a lot fatter' were combined as 'want to be fatter'.

\section{Antbropometry}

Height was measured using a fibreglass tape on children without footwear, to $0 \cdot 2 \mathrm{~cm}$. Weight was measured in school clothing but without shoes using a calibrated digital scale (Home Health, model 8604; Dr Morepen Lab, Hong Kong) to the nearest $100 \mathrm{~g}$. BMI was computed and the BMI-for-age $Z$-score values ${ }^{(19)}$ were obtained using Anthroplus software version $1 \cdot 0 \cdot 2$ (WHO, Geneva, Switzerland). The recent WHO (2006) growth reference is based on data collected on children in the Multicentre Growth Reference Study and extrapolated on to the Centers for Disease Control and Prevention (2000) height and weight values ${ }^{(19)}$. These data also included children from India. These standards have also been used in other studies $^{(20,21)}$. Children were then categorized by weight status as overweight $(>+1 \mathrm{SD})$, normal weight $(-2 \mathrm{SD}$ to $+1 \mathrm{SD})$ and underweight $(<-2 \mathrm{SD})$.

While consent was obtained for a larger number of children, data were not obtained on all as some children $(8 \cdot 4 \%)$ were absent on the day of data collection. Among those who consented, $1.5 \%$ did not participate again 
due to absenteeism. The proportion of absenteeism was equally distributed across classes in all of the schools.

Thus, final data were obtained on 1902 children for anthropometry and on 1877 children for the questionnaire.

\section{Statistical analyses}

Age of the children was categorized as $\leq 10$ years and $>10$ years $^{(22)}$. Location of the school was categorized as city and non-city (villages and small towns), while language of instruction was categorized as Kannada and English and used as a surrogate for SES. Maternal and paternal education were categorized as $\leq 7$ th grade and $>7$ th grade based on gross enrolment ratio in secondary education in India of about $50 \%{ }^{(23)}$. Spearman rank's correlation was used to find the correlation between BMI $Z$-score and perception of current body weight. Perception of current body weight was cross-tabulated with weight status of the children. Discordance of perception with weight status was categorized as either underestimation (perception of being thinner compared with the current weight status) or overestimation (perception of being fatter compared with the current weight status).

Analysis was done using the SPSS statistical software package version 17 (SPSS Inc., Chicago, IL, USA). Categorical variables are reported as number and percentages. The $\chi^{2}$ test was used to find the association between sociodemographic characteristics and weight status of the children. The association of perception of current body weight as well as ideal body weight with various sociodemographic factors was also assessed using the $\chi^{2}$ test, and the unadjusted odds ratio is reported. Multinomial logistic regression analysis adjusted for age, gender, weight status of the children and sociodemographic factors was performed to identify the factors associated with under- and overestimation (reference: correct estimation) of current and ideal body weight perception. A level of significance (two-sided) less than 5\% was considered statistically significant.

\section{Results}

Table 1 summarizes the characteristics of the children stratified by their actual weight status. Girls were more likely to be overweight and less likely to be underweight than boys $(P<0 \cdot 001)$. Older children $(>10$ years $)$ were more likely to be underweight than younger children $(\leq 10$ years; $P<0 \cdot 010)$. Children in cities were more likely to be overweight and less likely to be underweight compared with their non-city counterparts $(P<0 \cdot 001)$. Children in English-language schools were more likely to be overweight than children from Kannada-language schools $(P<0 \cdot 001)$, while mothers and fathers who were more educated were more likely to have overweight children $(P<0 \cdot 001)$. The correlation between the actual BMI Z-score and the perception of body weight was found to be significant $(r=0.359 ; P<0 \cdot 001)$.

Table 2 assesses the perception of current weight by actual weight status for the entire study group. Multinomial logistic regression analysis was performed to identify the factors associated with under- and overestimation (reference: correct estimation) of current body image and the adjusted odds ratios (AOR) are reported. Across the sociodemographic variables of gender, age group, location,

Table 1 Sociodemographic characteristics and weight status of the participants: schoolchildren aged 8-14 years, Karnataka State, South India, January-March 2008

\begin{tabular}{|c|c|c|c|c|c|c|c|}
\hline & \multicolumn{6}{|c|}{ Weight status } & \multirow[b]{3}{*}{$P^{*}$} \\
\hline & \multicolumn{2}{|c|}{ Underweight ( $n$ 476) } & \multicolumn{2}{|c|}{ Overweight ( $n$ 181) } & \multicolumn{2}{|c|}{ Normal weight ( $n$ 1245) } & \\
\hline & $n$ & $\%$ & $n$ & $\%$ & $n$ & $\%$ & \\
\hline \multicolumn{8}{|l|}{ Gender } \\
\hline Male & 271 & $30 \cdot 3$ & 74 & $8 \cdot 3$ & 548 & $61 \cdot 4$ & $<0.001$ \\
\hline Female & 205 & $20 \cdot 3$ & 107 & $10 \cdot 6$ & 697 & $69 \cdot 1$ & \\
\hline \multicolumn{8}{|l|}{ Age category } \\
\hline$\leq 10$ years & 153 & $21 \cdot 3$ & 67 & $9 \cdot 3$ & 498 & $69 \cdot 4$ & 0.010 \\
\hline$>10$ years & 323 & $27 \cdot 3$ & 114 & $9 \cdot 6$ & 747 & $63 \cdot 1$ & \\
\hline \multicolumn{8}{|l|}{ Location } \\
\hline Non-city & 357 & $29 \cdot 0$ & 98 & $8 \cdot 0$ & 776 & $63 \cdot 0$ & $<0.001$ \\
\hline City & 119 & $17 \cdot 7$ & 83 & $12 \cdot 4$ & 469 & $69 \cdot 9$ & \\
\hline \multicolumn{8}{|c|}{ Language of instruction } \\
\hline Kannada & 132 & $25 \cdot 3$ & 22 & $4 \cdot 2$ & 367 & $70 \cdot 4$ & $<0.001$ \\
\hline English & 344 & $24 \cdot 9$ & 159 & $11 \cdot 5$ & 878 & $63 \cdot 6$ & \\
\hline Education of mother & (n 374) & & $(n 141)$ & & (n 1020) & & \\
\hline$\leq 7$ th grade & 121 & $28 \cdot 5$ & 16 & $3 \cdot 8$ & 288 & $67 \cdot 8$ & $<0.001$ \\
\hline$>7$ th grade & 253 & $22 \cdot 8$ & 125 & $11 \cdot 3$ & 732 & $65 \cdot 9$ & \\
\hline Education of father & $(n$ 414) & & $(n$ 161) & & $(n$ 1101) & & \\
\hline$\leq 7$ th grade & 101 & $24 \cdot 3$ & 23 & $5 \cdot 5$ & 292 & $70 \cdot 2$ & 0.003 \\
\hline$>7$ th grade & 313 & $24 \cdot 8$ & 138 & $11 \cdot 0$ & 809 & $64 \cdot 2$ & \\
\hline
\end{tabular}

${ }^{*} P$ value obtained through Pearson's $\chi^{2}$ test. 
Table 2 Concordance and discordance: perception of current body weight across sociodemographic and weight status categories among schoolchildren aged 8-14 years, Karnataka State, South India, January-March 2008

\begin{tabular}{|c|c|c|c|c|c|c|c|c|c|c|c|c|c|c|}
\hline \multirow[b]{2}{*}{ Variable } & \multicolumn{2}{|c|}{ Correct estimation } & \multicolumn{6}{|c|}{ Underestimation } & \multicolumn{6}{|c|}{ Overestimation } \\
\hline & $n$ & $\%$ & $n$ & $\%$ & $\begin{array}{c}\text { Unadjusted } \\
\text { OR }\end{array}$ & $95 \% \mathrm{Cl}$ & $\begin{array}{c}\text { Adjusted } \\
\text { ORt }\end{array}$ & $95 \% \mathrm{Cl}$ & $n$ & $\%$ & $\begin{array}{c}\text { Unadjusted } \\
\text { OR }\end{array}$ & $95 \% \mathrm{Cl}$ & $\begin{array}{l}\text { Adjusted } \\
\text { ORt }\end{array}$ & $95 \% \mathrm{Cl}$ \\
\hline \multicolumn{15}{|l|}{ Gender } \\
\hline Boys & 392 & $46 \cdot 4$ & 213 & $25 \cdot 2$ & 0.90 & $0 \cdot 72,1 \cdot 14$ & 0.96 & $0.74,1.25$ & 240 & $28 \cdot 4$ & $1 \cdot 16$ & $0.92,1.46$ & 0.90 & $0.67,1 \cdot 21$ \\
\hline Girlst & 452 & $47 \cdot 0$ & 272 & $28 \cdot 3$ & & & & & 238 & $24 \cdot 7$ & & & & \\
\hline \multicolumn{15}{|l|}{ Age category } \\
\hline$\leq 10$ years & 307 & $45 \cdot 1$ & 217 & 31.9 & $1 \cdot 42^{\star \star}$ & $1 \cdot 12,1 \cdot 79$ & $1 \cdot 63^{\star \star \star}$ & $1 \cdot 25,2 \cdot 11$ & 157 & $23 \cdot 1$ & $0 \cdot 86$ & $0.67,1.09$ & $0 \cdot 84$ & $0 \cdot 62,1 \cdot 14$ \\
\hline$>10$ years $\ddagger$ & 537 & $47 \cdot 7$ & 268 & $23 \cdot 8$ & & & & & 321 & $28 \cdot 5$ & & & & \\
\hline \multicolumn{15}{|l|}{ Location } \\
\hline Non-city & 528 & $45 \cdot 1$ & 301 & $25 \cdot 7$ & 0.98 & $0 \cdot 77,1 \cdot 24$ & $1 \cdot 04$ & $0 \cdot 79,1 \cdot 36$ & 342 & $29 \cdot 2$ & $1 \cdot 51^{\star *}$ & $1 \cdot 18,1 \cdot 92$ & $1 \cdot 24$ & $0.91,1 \cdot 70$ \\
\hline City $\ddagger$ & 316 & $49 \cdot 7$ & 184 & $28 \cdot 9$ & & & & & 136 & $21 \cdot 4$ & & & & \\
\hline \multicolumn{15}{|l|}{$\begin{array}{l}\text { Language of } \\
\text { instruction }\end{array}$} \\
\hline Kannada & 201 & $40 \cdot 4$ & 164 & $32 \cdot 9$ & $1 \cdot 63^{\star \star \star}$ & $1 \cdot 27,2 \cdot 11$ & $1 \cdot 87^{\star \star \star}$ & $1 \cdot 32,2 \cdot 65$ & 133 & $26 \cdot 7$ & $1 \cdot 23$ & $0.95,1.60$ & 1.45 & $0 \cdot 98,2 \cdot 14$ \\
\hline English $\ddagger$ & 643 & $49 \cdot 1$ & 321 & $24 \cdot 5$ & & & & & 345 & $26 \cdot 4$ & & & & \\
\hline \multicolumn{15}{|l|}{ Education of mother } \\
\hline$\leq 7$ th grade & 167 & $40 \cdot 4$ & 126 & $29 \cdot 1$ & $1 \cdot 41^{* *}$ & $1 \cdot 06,1 \cdot 87$ & $1 \cdot 08$ & $0.77,1.53$ & 120 & $29 \cdot 1$ & $1 \cdot 38^{\star *}$ & $1 \cdot 03,1 \cdot 83$ & $1 \cdot 01$ & $0.69,1.47$ \\
\hline$>7$ th grade $\neq$ & 527 & $48 \cdot 6$ & 282 & $25 \cdot 4$ & & & & & 275 & $25 \cdot 4$ & & & & \\
\hline \multicolumn{15}{|l|}{ Education of father } \\
\hline$\leq 7$ th grade & 165 & $40 \cdot 6$ & 138 & $34 \cdot 0$ & $1 \cdot 66^{\star \star \star}$ & $1 \cdot 26,2 \cdot 18$ & $1 \cdot 37$ & $0.96,1.95$ & 103 & $25 \cdot 4$ & $1 \cdot 14$ & $0 \cdot 86,1 \cdot 53$ & 1.09 & $0 \cdot 72,1 \cdot 64$ \\
\hline$>7$ th grade $\neq$ & 601 & $48 \cdot 8$ & 303 & $24 \cdot 6$ & & & & & 328 & $26 \cdot 6$ & & & & \\
\hline \multicolumn{15}{|l|}{ Weight status } \\
\hline Underweight & 115 & $25 \cdot 4$ & 39 & $8 \cdot 6$ & $0 \cdot 67^{\star \star *}$ & $0.46,0.98$ & $0 \cdot 72$ & $0 \cdot 46,1 \cdot 11$ & 298 & 65.9 & $10 \cdot 10^{\star \star *}$ & $7 \cdot 65,13 \cdot 19$ & $10 \cdot 50^{\star \star \star}$ & $7 \cdot 70,14 \cdot 44$ \\
\hline Overweight & 58 & $33 \cdot 7$ & 107 & $62 \cdot 2$ & $3 \cdot 65^{\star \star \star}$ & $2 \cdot 58,5 \cdot 16$ & $4 \cdot 66^{\star \star \star}$ & $3 \cdot 10,7 \cdot 03$ & 7 & $4 \cdot 1$ & 0.47 & $0 \cdot 21,1 \cdot 04$ & 0.69 & $0.30,1.59$ \\
\hline Normal weight‡ & 671 & $56 \cdot 7$ & 339 & $28 \cdot 7$ & & & & & 173 & $14 \cdot 6$ & & & & \\
\hline
\end{tabular}

${ }^{* \star} P \leq 0.01,{ }^{* * \star} P<0.001$

tAdjusted for age, gender and weight status of children and sociodemographic factors.

‡Reference group. 
Table 3 Body weight satisfaction: perception of 'ideal' body weight across sociodemographic and weight status categories among schoolchildren aged 8-14 years, Karnataka State, South India, January-March 2008

\begin{tabular}{|c|c|c|c|c|c|c|c|c|c|c|c|c|c|c|}
\hline \multirow[b]{2}{*}{ Variable } & \multicolumn{2}{|c|}{ Want to be as I am } & \multicolumn{6}{|c|}{ Want to be thinner } & \multicolumn{6}{|c|}{ Want to be fatter } \\
\hline & $n$ & $\%$ & $n$ & $\%$ & $\begin{array}{l}\text { Unadjusted } \\
\text { OR }\end{array}$ & $95 \% \mathrm{Cl}$ & $\begin{array}{l}\text { Adjusted } \\
\text { ORt }\end{array}$ & $95 \% \mathrm{Cl}$ & $n$ & $\%$ & $\begin{array}{l}\text { Unadjusted } \\
\text { OR }\end{array}$ & $95 \% \mathrm{Cl}$ & $\begin{array}{l}\text { Adjusted } \\
\text { ORt }\end{array}$ & $95 \% \mathrm{Cl}$ \\
\hline \multicolumn{15}{|l|}{ Gender } \\
\hline $\begin{array}{l}\text { Boys } \\
\text { Girlsł }\end{array}$ & $\begin{array}{l}437 \\
470\end{array}$ & $\begin{array}{l}49 \cdot 9 \\
47 \cdot 0\end{array}$ & $\begin{array}{l}200 \\
300\end{array}$ & $\begin{array}{l}22 \cdot 9 \\
30 \cdot 0\end{array}$ & $0 \cdot 72^{\star \star}$ & $0.57,0.90$ & $0 \cdot 69^{\star \star}$ & $0.53,0.90$ & $\begin{array}{l}238 \\
230\end{array}$ & $\begin{array}{l}27 \cdot 2 \\
23 \cdot 0\end{array}$ & $1 \cdot 11$ & $0 \cdot 88,1 \cdot 40$ & 0.97 & $0 \cdot 75,1 \cdot 26$ \\
\hline \multicolumn{15}{|l|}{ Age category } \\
\hline $\begin{array}{l}\leq 10 \text { years } \\
>10 \text { years } \ddagger\end{array}$ & $\begin{array}{l}341 \\
566\end{array}$ & $\begin{array}{l}48 \cdot 3 \\
48 \cdot 4\end{array}$ & $\begin{array}{l}174 \\
326\end{array}$ & $\begin{array}{l}24 \cdot 6 \\
27 \cdot 9\end{array}$ & $0 \cdot 89$ & $0 \cdot 70,1 \cdot 12$ & $0 \cdot 79$ & $0.61,1.04$ & $\begin{array}{l}191 \\
277\end{array}$ & $\begin{array}{l}27 \cdot 1 \\
23 \cdot 7\end{array}$ & $1 \cdot 14$ & $0 \cdot 91,1 \cdot 45$ & $1 \cdot 16$ & $0.89,1.51$ \\
\hline \multicolumn{15}{|l|}{ Location } \\
\hline $\begin{array}{l}\text { Non-city } \\
\text { City }\end{array}$ & $\begin{array}{l}598 \\
309\end{array}$ & $\begin{array}{l}48 \cdot 8 \\
47 \cdot 5\end{array}$ & $\begin{array}{l}295 \\
205\end{array}$ & $\begin{array}{l}24 \cdot 1 \\
31 \cdot 5\end{array}$ & $0 \cdot 74^{\star \star \star}$ & $0.59,0.94$ & 0.86 & $0 \cdot 66,1 \cdot 13$ & $\begin{array}{l}332 \\
136\end{array}$ & $\begin{array}{l}27 \cdot 1 \\
20 \cdot 9\end{array}$ & $1 \cdot 26$ & $0.98,1.62$ & $1 \cdot 14$ & $0 \cdot 86,1 \cdot 51$ \\
\hline \multicolumn{15}{|l|}{$\begin{array}{l}\text { Language of } \\
\text { instruction }\end{array}$} \\
\hline $\begin{array}{l}\text { Kannada } \\
\text { English } \ddagger\end{array}$ & $\begin{array}{l}275 \\
632\end{array}$ & $\begin{array}{l}53 \cdot 8 \\
46 \cdot 3\end{array}$ & $\begin{array}{r}94 \\
406\end{array}$ & $\begin{array}{l}18 \cdot 4 \\
29 \cdot 8\end{array}$ & $0.53^{\star \star \star}$ & $0.40,0.69$ & $0 \cdot 45^{\star \star \star}$ & $0.31,0.66$ & $\begin{array}{l}142 \\
326\end{array}$ & $\begin{array}{l}27 \cdot 8 \\
23 \cdot 9\end{array}$ & $1 \cdot 00$ & $0 \cdot 78,1 \cdot 29$ & $0 \cdot 81$ & $0 \cdot 58-1 \cdot 14$ \\
\hline \multicolumn{15}{|l|}{ Education of mother } \\
\hline $\begin{array}{l}\leq 7 \text { th grade } \\
>7 \text { th grade } \neq\end{array}$ & $\begin{array}{l}217 \\
543\end{array}$ & $\begin{array}{l}50 \cdot 8 \\
48 \cdot 3\end{array}$ & $\begin{array}{r}92 \\
320\end{array}$ & $\begin{array}{l}21 \cdot 5 \\
28 \cdot 4\end{array}$ & $0 \cdot 72^{\star \star}$ & $0.54,0.96$ & $1 \cdot 01$ & $0 \cdot 72,1 \cdot 44$ & $\begin{array}{l}118 \\
262\end{array}$ & $\begin{array}{l}27 \cdot 6 \\
23 \cdot 3\end{array}$ & $1 \cdot 13$ & $0 \cdot 85,1 \cdot 49$ & $1 \cdot 15$ & $0.83,1.59$ \\
\hline \multicolumn{15}{|l|}{ Education of father } \\
\hline $\begin{array}{l}\leq 7 \text { th grade } \\
>7 \text { th grade } \neq\end{array}$ & $\begin{array}{l}198 \\
620\end{array}$ & $\begin{array}{l}47 \cdot 3 \\
48 \cdot 6\end{array}$ & $\begin{array}{l}102 \\
353\end{array}$ & $\begin{array}{l}24 \cdot 3 \\
27 \cdot 7\end{array}$ & 0.90 & $0 \cdot 68,1 \cdot 20$ & $1 \cdot 43$ & $0 \cdot 99,2 \cdot 07$ & $\begin{array}{l}119 \\
302\end{array}$ & $\begin{array}{l}28 \cdot 4 \\
23 \cdot 7\end{array}$ & $1 \cdot 23$ & $0.94,1 \cdot 62$ & $1 \cdot 27$ & $0 \cdot 89,1 \cdot 80$ \\
\hline \multicolumn{15}{|l|}{ Weight status } \\
\hline Underweight & 224 & $49 \cdot 3$ & 85 & $18 \cdot 7$ & $0 \cdot 71^{\star \star \star}$ & $0.53,0.95$ & $0 \cdot 63^{\star \star \star}$ & $0 \cdot 45,0 \cdot 88$ & 145 & $31 \cdot 9$ & $1 \cdot 38$ & $1 \cdot 07,1 \cdot 80$ & $1 \cdot 25$ & $0.93,1.67$ \\
\hline Overweight & 60 & $35 \cdot 3$ & 83 & $48 \cdot 8$ & $2 \cdot 59^{\star \star \star}$ & $1 \cdot 78,3 \cdot 77$ & $2 \cdot 51^{\star \star \star}$ & $1 \cdot 65,3 \cdot 81$ & 27 & $15 \cdot 9$ & 0.96 & $0.58,1.59$ & $1 \cdot 13$ & $0.65,1.91$ \\
\hline Normal weight‡ & 590 & $50 \cdot 0$ & 315 & $26 \cdot 7$ & & & & & 276 & $23 \cdot 4$ & & & & \\
\hline
\end{tabular}

${ }^{*} P \leq 0.01,{ }^{* * \star} P<0.001$

tAdjusted for age, gender and weight status of the children and sociodemographic factors.

‡Reference group. 
language of instruction and education of parents, less than $50 \%$ of children correctly perceived their current weight status. Even among children of normal weight, only $56.7 \%$ felt they were of normal weight. Among underweight children only $25.4 \%$ perceived their body weight status correctly, while the percentage was $33.7 \%$ among overweight children. Younger children were more likely to underestimate their current weight status, i.e. perceive themselves to be thinner than they actually were (AOR = $1 \cdot 63,95 \%$ CI $1 \cdot 25,2 \cdot 11 ; P<0 \cdot 001$ ), than older children. Likewise, children from Kannada-language schools (lower SES) were more likely than those from the Englishlanguage schools to underestimate their current weight status; this underestimation of current body weight was significant even after adjusting for all other factors, including current weight status $(\mathrm{AOR}=1 \cdot 87,95 \% \mathrm{CI} 1 \cdot 32,2 \cdot 65$; $P<0 \cdot 001)$. The strongest associations of discordance of body weight perception and actual body weight were with current anthropometric status; thus children who were underweight were more than ten times more likely to overestimate their weight status, i.e. perceive themselves to be heavier than they actually were $(\mathrm{AOR}=10 \cdot 50,95 \% \mathrm{CI}$ 7.70, 14.44; $P<0.001$ ), while overweight children were about four times more likely to perceive themselves to be thinner than they actually were $(\mathrm{AOR}=4 \cdot 66,95 \% \mathrm{CI} 3 \cdot 10$, 7.03; $P<0 \cdot 001)$.

Children's perception of their 'ideal' body weight (Table 3) across sociodemographic and anthropometric categories was analysed. Across sociodemographic categories approximately $50 \%$ of children wanted to remain within their current weight category. Some $49 \cdot 3 \%$ of underweight children and $35 \cdot 3 \%$ of overweight children also wished to remain within the same weight category. Boys were less likely to want to be thinner, even after adjusting for other factors including current anthropometric status $(\mathrm{AOR}=0 \cdot 69,95 \% \mathrm{CI} 0 \cdot 53,0 \cdot 90 ; P \leq 0 \cdot 01)$. Children of less educated mothers and from outside the city were also less likely to want to be thinner, but these were no longer significant when adjusted for other factors. Children from schools with Kannada as language of instruction (low SES) were less likely to want to be thinner, even after adjusting for other factors (AOR $=0 \cdot 45,95 \%$ CI $0 \cdot 31,0 \cdot 66 ; P<0 \cdot 001$ ) including actual weight status. Children who were currently overweight were two times more likely to want to be thinner (AOR $=2 \cdot 51, \quad 95 \%$ CI $1.65, \quad 3 \cdot 81 ; \quad P<0 \cdot 001)$, while underweight children were less likely to want to be thinner after adjusting for other factors (AOR $=0 \cdot 63,95 \%$ CI $0 \cdot 45,0 \cdot 88 ; P<0 \cdot 001)$.

\section{Discussion}

The present data suggest that SES is one of the major factors associated with current perception of body weight, which reflects perception of body image. The most important factor associated with a different desired body weight appeared to be current weight status. There were also important gender differences.

In countries like Pakistan, Brazil, Malaysia and India, the prevalence of overweight and obesity is comparatively higher in children residing in urban compared with rural areas ${ }^{(24-28)}$. Similar findings are noted in our data. In contrast to studies that have reported a greater prevalence of overweight individuals in economically and socially disadvantaged families in developed countries ${ }^{(28,29)}$, our data indicate that overweight is a problem of the higher socio-economic group (using language of instruction as a surrogate). There is now an increasing body of evidence suggesting that overweight in adults and adolescents is beginning to increase in the urban poor ${ }^{(2,30)}$. This may be a reflection of the phase of the nutrition transition.

Body image represents an individual's subjective experience with his/her body and the manner in which he/she organizes this experience ${ }^{(31)}$. Although attitude towards body image appears in girls as young as 5-6 years of age ${ }^{(32-34)}$, a larger number become aware of it during adolescence and young adulthood ${ }^{(35)}$. Perception of one's body image can be influenced by self-esteem, selfevaluation and evaluation by others ${ }^{(36)}$. Satisfaction with body image depends on whether the body form of an individual conforms to the desired body image. Our data on perception of weight in children indicate that younger children perceive themselves to be thinner than their actual weight compared with older children. This may be because fewer younger children have developed an attitude towards body image due to lower cognitive development ${ }^{(35)}$; other possible reasons need to be explored further. Overweight children had higher odds of perceiving themselves to be thinner than they actually were; this implies that awareness of their overweight status is lacking. Similar findings are reported among certain ethnic populations where overweight is viewed positively and considered normal, and this probably reflects their culturally accepted ideal body image ${ }^{(37,38)}$. Socio-culturally desired body weight in India needs to be examined and must be taken into account while designing interventions to combat overweight and obesity in Indian children. Likewise, the very high odds of underweight children perceiving themselves to be much heavier than they actually are could have other potential adverse consequences; for instance, participation in school meal programmes ${ }^{(39,40)}$ aimed at addressing the issue of undernutrition.

While our study did not show significant differences in perceived current body weight between boys and girls, perceived body image dissatisfaction has been observed in both males and females in children and adolescents ${ }^{(41)}$. When perceived image differs from the ideal image there can be varied levels of distress. Very low body image distress or concern may evoke either little or no motivation to change body weight, while those with very high 
body image distress are more likely to use unhealthy weight-correction methods ${ }^{(42,43)}$. Our data do indicate, however, that boys are less likely to want to be thinner than they currently are. It would be interesting to determine which of these variables - desired body image perception or actual body weight status - is more closely associated with dietary and physical activity patterns, actual weight gain or decrease over time and personal interventions aimed at weight control, if any.

In India $34 \%$ of men and $36 \%$ of women between 15 and 49 years of age are underweight ${ }^{(3)}$. Although underweight and overweight coexist in developing countries, in the last two decades overweight has increased and underweight has decreased among schoolgoing children ${ }^{(24,44)}$. In the future, underweight is predicted to reduce further by one-third while overweight/ obesity may continue to increase ${ }^{(45)}$. In India, the transition from underweight has been slower; data from the two cross-sectional National Family and Health Surveys conducted in 1998-1999 and 2005-2006 indicate that in children less than 3 years of age, underweight and stunting have reduced from $42 \cdot 7 \%$ and $51 \cdot 0 \%$ to $40 \cdot 4 \%$ and $44.9 \%$, respectively ${ }^{(3)}$. This high burden of underweight and the discordance of perceived body weight and actual weight status suggest that feedback on weight status to students may be important. Currently, schools do measure heights and weights of students on an annual basis, but there is little feedback provided to students or parents.

Body image perception and dissatisfaction has emerged as a health issue among a large section of young individuals $^{(41)}$ in certain populations. Accurate perception of weight is important in both underweight and overweight individuals. Dissatisfaction within these groups can worsen malnutrition along with the consequences of disease related to it ${ }^{(10,46)}$. This is particularly true in the specific context of India where the prevalence of underweight is still very high. The result that children who were underweight were more than ten times more likely to perceive themselves to be heavier than they really are is worrisome because it can hamper the implementation of measures to prevent and control malnutrition. The mistaken perception on the current weight of both underweight and overweight children suggests that the dissatisfaction with body weight that was observed in $50 \%$ of individuals could be worse if they had the correct perception about their nutritional status. The challenge would be to find cost-effective, easily implementable and scalable ways to improve the perception of current weight and acceptance of one's body, thus minimizing the risks of an inadequate diet for weight correction. Intervention at school may be the first choice in an attempt to improve body weight perception in preadolescents and adolescents. Adequate training is necessary to prepare personnel at schools so that they can promote a healthy and positive body image ${ }^{(47)}$.

\section{Strengths and limitations of the study}

The present study is an exploration of perceived body image in schoolchildren using simple questions. Greater insights may be obtained in future by employing qualitative methods to explore the themes that have emerged as findings in our study. SES was determined using language of instruction as a surrogate; this is clearly only one indicator and may reflect issues other than economic status, such as greater knowledge about weight status and health in general. Anthropometric assessment was limited to height and weight. In future studies it will be useful to also include additional measures of central adiposity e.g. waist and hip circumference, since an increased propensity towards central obesity is a particular problem of South Asians ${ }^{(48)}$. Dietary and physical activity patterns were not captured at the time of the current assessment; this would be important to study in future work, in order to determine the extent to which body image perception $v$. actual body weight is associated with these behaviours. It would also be important to determine in longitudinal studies whether desired body image is associated with later weight gain or weight loss.

\section{Conclusions}

Overall, the present data indicate that SES influences body weight perception of children, with children from schools with Kannada as language of instruction being more likely to underestimate their current weight status, as well as being less likely to want to be thinner, than children studying in schools with English as language of instruction. In general, only about $50 \%$ of children correctly perceived their current weight status whether they were of normal weight, underweight or overweight. Underweight children were more likely to overestimate their weight status and overweight children more likely to underestimate it. Body weight perception of children has to be taken into account when designing and implementing programmes to combat both underweight and overweight in children.

\section{Acknowledgements}

The present study was conducted with intra-mural funding. The authors declare that they have no conflicts of interest. M.P., S.Sw. and M.V. designed the study. M.P. acquired the data and drafted the manuscript. S.Se. performed the statistical analysis and interpretation of data. S.Sw. helped to draft the manuscript and critically revise it. M.V. conceived of the study, interpreted the data, helped draft the manuscript and critically revise it. All authors read and approved the final manuscript. The authors thank Dr Roopashree for help in data acquisition and entry. 


\section{References}

1. Kaur S \& Kapil U (2008) Prevalence of overweight and obesity in school children in Delhi. Indian Pediatr 45, 330-331.

2. Bhardwaj S, Misra A, Khurana L et al. (2008) Childhood obesity in Asian Indians: a burgeoning cause of insulin resistance, diabetes and sub-clinical inflammation. Asia Pac J Clin Nutr 17, Suppl. 1, 172-175.

3. International Institute for Population Sciences \& ORC Macro International (2007) National Family Health Survey (NFHS-3), 2005-2006: India, Volume 1. Mumbai: IIPS.

4. Yang X, Telama R, Viikari J et al. (2006) Risk of obesity in relation to physical activity tracking from youth to adulthood. Med Sci Sports Exerc 38, 919-925.

5. Swaminathan S, Thomas T, Kurpad AV et al. (2007) Dietary patterns in urban school children in South India. Indian Pediatr 44, 593-596.

6. Kuriyan R, Bhat S, Thomas $\mathrm{T}$ et al. (2007) Television viewing and sleep are associated with overweight among urban and semi-urban South Indian children. Nutr J 6, 25.

7. Thompson J (1990) Body Image Disturbance: Assessment and Treatment. New York: Pergamon Press.

8. Cachelin FM, Rebeck RM, Chung GH et al. (2002) Does ethnicity influence body-size preference? A comparison of body image and body size. Obes Res 10, 158-166.

9. Neff LJ, Sargent RG, McKeown RE et al. (1997) Black-white differences in body size perceptions and weight management practices among adolescent females. J Adolesc Health 20, 459-465.

10. Bhuiyan AR, Gustat J, Srinivasan SR et al. (2003) Differences in body shape representations among young adults from a biracial (black-white), semirural community: the Bogalusa Heart Study. Am J Epidemiol 158, 792-797.

11. Rastogi T, Reddy KS, Vaz M et al. (2004) Diet and risk of ischemic heart disease in India. Am J Clin Nutr 79, 582-592.

12. Viner RM, Haines MM, Taylor SJ et al. (2006) Body mass, weight control behaviours, weight perception and emotional well being in a multiethnic sample of early adolescents. Int J Obes (Lond) 30, 1514-1521.

13. Saxton J, Hill C, Chadwick P et al. (2009) Weight status and perceived body size in children. Arch Dis Child 94, 944-949.

14. Haff DR (2009) Racial/ethnic differences in weight perceptions and weight control behaviors among adolescent females. Youth Soc 41, 278-301.

15. Abbott RA, Lee AJ, Stubbs CO et al. (2010) Accuracy of weight status perception in contemporary Australian children and adolescents. J Pediatr Child Health 46, 343-348.

16. Edwards NM, Pettingell S \& Borowsky IW (2010) Where perception meets reality: self perception of weight in overweight adolescents. Pediatrics 125, e452-e458.

17. Maximova K, McGrath JJ, Barbnett T et al. (2008) Do you see what I see? Weight status misperception and exposure to obesity among children and adolescents. Int $J$ Obes (Lond) 32, 1008-1015.

18. Martin MA, Ashleigh LM \& Michelle LF (2010) Equal weights but different weight perceptions among US adolescents. J Health Psychol 15, 493-504.

19. de Onis M, Onyango A, Borghi E et al. (2007) Development of a WHO growth reference for school-aged children and adolescents. Bull World Health Organ 85, 660-667.

20. Stein AD, Wang M, DiGirolamo A et al. (2009) Height for age increased while body mass index for age remained stable between 1968 and 2007 among Guatemalan children. J Nutr 139, 365-369.

21. Deurenberg-Yap M, Niti M, Foo LL et al. (2009) Diagnostic accuracy of anthropometric indices for obesity screening among Asian adolescents. Ann Acad Med Singapore 38, 3-8.

22. World Health Organization (2005) Nutrition in Adolescence. Issues and Challenges for the Health Sector. Discussion Paper. WHO: Geneva.
23. United Nations Educational, Scientific and Cultural Organization (2010) UIS Statistics in Brief. Education (all levels) profile - India. http://stats.uis.unesco.org/unesco/ TableViewer/document.aspx?ReportId=121\&IF_Language $=$ eng\&BR_Country $=3560$ (accessed January 2010).

24. Wang Y, Monteiro C \& Popkin BM (2002) Trends of obesity and underweight in older children and adolescents in the United States, Brazil, China, and Russia. Am J Clin Nutr $\mathbf{7 5}$, 971-977.

25. Raj M, Sundaram KR, Paul M et al. (2009) Dynamics of growth and weight transitions in a pediatric cohort from India. Nutr $J \mathbf{8}, 55$.

26. Jafar TH, Hatcher J \& Bhutta ZA (2008) Rapidly rising rates of overweight and obesity coupled with persistently high rates of undernutrition among school aged children in an urban Indo-Asian population: authors' response. Arch Dis Child 93, 1000-1001.

27. Dev R, Dev O, Perumal V et al. (2009) Rural urban differences in body image perception, body mass index and dieting behaviour among adolescent Malaysian school girls. Eur J Sci Res 34, 69-82.

28. Goodman E (1999) The role of socioeconomic status gradients in explaining differences in US adolescents' health. Am J Public Health 89, 1522-1528.

29. Sobal J \& Stunkard AJ (1989) Socioeconomic status and obesity: a review of the literature. Psychol Bull 105, 260-275.

30. Mohan V \& Deepa R (2006) Obesity and abdominal obesity in Asian Indians. Indian J Med Res 123, 593-596.

31. McElhone S, Kearney JM, Giachetti I et al. (1999) Body image perception in relation to recent weight changes and strategies for weight loss in a nationally representative sample in the European Union. Public Health Nutr 2, 143-151.

32. Schur EA, Sanders M \& Steiner H (2000) Body dissatisfaction and dieting in young children. Int J Eat Disord 27, 74-82.

33. Tiggemann M (2005) Body dissatisfaction and adolescent self-esteem: prospective findings. Body Image 2, 129-135.

34. Davison KK \& Birch LL (2001) Weight status, parent reaction, and self-concept in five-year-old girls. Pediatrics 107, 46-53.

35. Australian Medical Association (2002) Body Image and Health. Barton ACT: Australian Medical Association.

36. Croll J (2005) Body image and adolescents. In Guidelines for Adolescent Nutrition Services, pp. 155-166 [J Stang and M Story, editors]. Minneapolis, MN: Center for Leadership, Education and Training in Maternal and Child Nutrition, Division of Epidemiology and Community Health, School of Public Health, University of Minnesota.

37. Paeratakul S, White MA, Williamson DA et al. (2002) Sex, race/ethnicity, socioeconomic status, and BMI in relation to self-perception of overweight. Obes Res 10, 345-350.

38. Dorsey RR, Eberhardt MS \& Ogden CL (2009) Racial/ethnic differences in weight perception. Obesity (Silver Spring) 17, 790-795.

39. Chakraborty P \& Anderson AK (2010) Predictors of overweight in children under 5 years of age in India. Curr Res J Soc Sci 2, 138-146.

40. Jequier E (2001) Is fat intake a risk factor for fat gain in children? J Clin Endocrinol Metab 86, 980-983.

41. O'Dea JA (1995) Body image and nutritional status among adolescents and adults $-\mathrm{a}$ review of literature. Aust J Nutr Diet 52, 56-67.

42. Heinberg LJ, Thompson J \& Matzon JL (2001) Body Image Dissatisfaction As a Motivator for Lifestyle Change: Is Some Distress Beneficial? Washington, DC: American Psychological Association.

43. Heinberg LJ, Thompson J \& Matzon JL (2005) The Role of Body Image Distress in Obesity: Is It Motivating or Malevolent? Proceedings of the International Conference on Eating Disorders, p. 6. Montreal, QC: Academy for Eating Disorders. 
44. Wold Health Organization (2003) Global Strategy on Diet, Physical Activity and Health. Geneva: WHO.

45. de Onis M, Blossner M, Borghi E et al. (2004) Estimates of global prevalence of childhood underweight in 1990 and 2015. JAMA 291, 2600-2606.

46. Kuchler F \& Variyam J (2003) Mistakes were made: misperception as a barrier to reducing overweight. Int J Obes Relat Metab Disord 27, 856-861.
47. Yager Z \& O'Dea JA (2005) The role of teachers and other educators in the prevention of eating disorders and child obesity: what are the issues? Eat Disord 13, 261-278.

48. Huxley R, Mendis S, Zheleznyakov E et al. (2010) Body mass index, waist circumference and waist:hip ratio as predictors of cardiovascular risk - a review of the literature. Eur J Clin Nutr 64, 16-22. 